\title{
Correction to: Properties of Interfaced Materials and Films: Part I
}

\author{
SUFIAN M. ABEDRABBO, ${ }^{1,2,4}$ ANTHONY T. FIORY, ${ }^{3,5}$ \\ and NUGGEHALLI M. RAVINDRA (10 ${ }^{3,6}$ \\ 1.-Department of Physics, Khalifa University, Abu Dhabi, UAE. 2.-Department of Physics, \\ University of Jordan, Amman, Jordan. 3.-New Jersey Institute of Technology, Newark, NJ, USA. \\ 4.-e-mail: sufian.abedrabbo@ku.ac.ae. 5.—e-mail: fiory@alum.mit.edu.6.—e-mail: nmravindra@ \\ gmail.com
}

Correction to: JOM, Vol. 71, No. 10, 2019

https://doi.org/10.1007/s11837-019-03729-9

The affiliation and respective footnotes for Sufian M. Abedrabbo and affiliation for Anthony T. Fiory were denoted incorrectly on the original publication of this article. They appear correctly here.
Publisher's Note Springer Nature remains neutral with regard to jurisdictional claims in published maps and institutional affiliations. 